\title{
Cultura Cultura
}

Revista de Historia Teorid das ldeaias - Revista de História e Teoria das Ideias

Vol. 22 | 2006

Ideias políticas

\section{O Conselho de Estado na Monarquia Constitucional}

Uma reflexão preliminar

The State Council in the Portuguese Constitutional Monarchy

\section{Pedro Tavares de Almeida}

\section{OpenEdition}

Journals

Edição electrónica

URL: http://journals.openedition.org/cultura/2232

DOI: 10.4000/cultura.2232

ISSN: 2183-2021

Editora

Centro de História da Cultura

Edição impressa

Data de publição: 1 Janeiro 2006

Paginação: 195-212

ISBN: 0870-4546

ISSN: 0870-4546

Refêrencia eletrónica

Pedro Tavares de Almeida, «O Conselho de Estado na Monarquia Constitucional », Cultura [Online], Vol. 22 | 2006, posto online no dia 20 dezembro 2015, consultado a 19 abril 2019. URL : http:// journals.openedition.org/cultura/2232 ; DOI : 10.4000/cultura.2232

Este documento foi criado de forma automática no dia 19 Abril 2019.

(c) CHAM - Centro de Humanidades / Centre for the Humanities 


\title{
O Conselho de Estado na Monarquia Constitucional
}

\author{
Uma reflexão preliminar \\ The State Council in the Portuguese Constitutional Monarchy
}

Pedro Tavares de Almeida

1 O presente artigo começa por descrever sinteticamente as mudanças observadas na composição e atribuições do Conselho de Estado durante a Monarquia Constitucional, procurando a seguir indagar, de modo ainda exploratório, qual foi a relevância política deste órgão de aconselhamento do Rei. As informações recolhidas indicam que, em geral, o Conselho de Estado era regularmente convocado pelos monarcas - sendo a maior ou menor frequência ditada pela gravidade das circunstâncias ou urgência dos assuntos - e que várias decisões régias sobre matérias controversas foram influenciadas pela opinião maioritária entre os conselheiros. A finalizar, o artigo apresenta uma biografia colectiva dos conselheiros efectivos entre 1833 e 1910, focando algumas características sociodemográficas (naturalidade, idade, grau de instrução, profissão, títulos nobiliárquicos) e o tipo de experiência política.

\section{Composição, atribuições e papel político do Conselho de Estado}

Instituição com raízes ancestrais, cujas origens remontam à cúria régia medieval, o Conselho de Estado, renovado nas suas competências e composição, foi um dos órgãos que transitou para a nova arquitectura do poder político desenhada pelo constitucionalismo liberal. ${ }^{1}$

3 A Constituição de 1822 consagrou-o como uma alta instância de consulta privada do Rei, que este convocava para se aconselhar na deliberação de "negócios graves" - em particular, quando se tratasse de "dar ou negar a sanção às leis, declarar a guerra e a paz e fazer tratados" (art. 167) -, competindo-lhe ainda propor ao soberano listas de nomes para o provimento dos lugares da magistratura e dos bispados. Os treze membros que 
formavam esta corporação consultiva, recrutados "entre as pessoas mais distintas por seus conhecimentos e virtudes", que tivessem no mínimo 35 anos de idade, eram escolhidos pelo Rei a partir de listas tríplices propostas pelas Cortes. Os conselheiros eram nomeados por um período de quatro anos, findo o qual podiam ser reconduzidos, desde que incluídos nas novas listas saídas das Cortes. Como é sabido, o ordenamento constitucional vintista teve, no entanto, uma efémera duração, sendo desmantelado a seguir ao triunfo do movimento contra-revolucionário da Vilafrancada (Maio de 1823).

Na Carta Constitucional de 1826, o Conselho de Estado ressurgiu como órgão consultivo do monarca, mas com um figurino alterado. Para além de um membro de direito próprio (o Príncipe Real, assim que completasse dezoito anos), era constituído por conselheiros vitalícios nomeados livremente pelo Rei, deixando assim de ser uma emanação das Cortes. A norma constitucional não estabelecia qualquer requisito na selecção dos conselheiros (excepto a interdição imposta à nomeação de estrangeiros, mesmo que naturalizados) e era igualmente omissa quanto ao seu número, mas este foi fixado em doze pelo Decreto de 19 de Setembro de 1833, que lhes atribuiu também um ordenado de $2.400 \$ 000$ réis anuais. Em virtude da consagração do "princípio monárquico", ainda que limitado por instituições representativas, a Carta ampliou as funções de assistência política do Conselho de Estado:

"Os Conselheiros serão ouvidos em todos os negócios graves, e medidas gerais de Pública Administração, principalmente sobre a declaração da guerra, ajustes de paz, negociações com as Nações Estrangeiras, assim como em todas as ocasiões, em que o Rei se proponha exercer qualquer das atribuições próprias do Poder Moderador" (art. 110²). [itálico nosso]

5 Assim, com a excepção (formal, pelo menos) da nomeação e demissão dos ministros, a auscultação dos conselheiros tornou-se obrigatória aquando da sanção régia das leis votadas nas Cortes, da nomeação de pares do reino, da dissolução da Câmara dos Deputados e da convocação extraordinária, prorrogação ou adiamento das Cortes. Além disso, devido à intimidade das funções dos poderes moderador e executivo, ${ }^{2}$ os actos correntes deste último podiam ser objecto da consulta do Rei ao Conselho de Estado, apesar de a norma constitucional o não prever. ${ }^{3}$

6 Ultrapassado o curto interregno setembrista, em que foi não só revogada a Carta como abolido o Conselho de Estado, este retomou a sua anterior posição no ordenamento constitucional, conhecendo embora uma importante reforma em $1845,{ }^{4}$ que alargou as suas competências legais e modificou a sua organização interna. Assim, a par da manutenção das anteriores funções eminentemente politicas, o Conselho de Estado passou a exercer competências puramente administrativas e tornou-se a instância suprema da jurisdição contenciosa da Administração. Para responder a essas novas exigências, de índole mais técnica, criaram-se os lugares de conselheiro extraordinário (doze, no máximo), a serem preenchidos por reputados juristas, e de ouvidor (até de zoito), confiados a bacharéis formados em Direito. O Conselho de Estado político funcionava separadamente das secções administrativa e do contencioso, em reunião plenária dos vogais efectivos - desde que houvesse um quorum de $2 / 3$-, sob a presidência do Rei.

7 Simetricamente, a reforma que teve lugar em 1870 voltou a confinar o Conselho de Estado, agora de modo definitivo, às suas atribuições políticas. ${ }^{5} \mathrm{~A}$ jurisdição contenciosa foi, então, transferida para o recém-criado Supremo Tribunal Administrativo, ao passo que as funções propriamente administrativas foram consignadas ao Procurador-Geral da 
Fazenda e da Coroa. Se estas últimas, segundo o testemunho informado de Joaquim Tomás Lobo de Ávila, e no que respeita sobretudo "a preparar propostas de lei, e a fazer projectos de regulamentos administrativos [...] nunca foram exercidas"6 pelo Conselho de Estado, já quanto ao contencioso o seu labor foi intenso, estabelecendo uma importante jurisprudência na matéria. ${ }^{7}$

No contexto europeu oitocentista, e mormente após a reforma de 1870, o Conselho de Estado português parece configurar uma instituição relativamente singular. Essa é, aliás, a conclusão do estudo comparativo feito pelo constitucionalista José Tavares no início do século XX:

"É interessante que, a não ser na Inglaterra, não há nos outros países, pelo menos nas Constituições do nosso conhecimento, instituição análoga ao nosso Conselho de Estado.

Há em quase todos, incluída a República Francesa, um Conselho de Estado. Não é, porém, um órgão de consulta e informação política do Chefe do Estado. É simplesmente um corpo administrativo de consulta do ministério, e contencioso administrativo para a resolução das questões suscitadas entre os cidadãos e a administração pública. É o nosso Supremo Tribunal Administrativo.

o Privy Council inglês foi outrora uma instituição quase idêntica, pelas suas funções, ao nosso Conselho de Estado; e foi de lá certamente que derivou a nossa instituição. [...] Mas, como diz Bruníalti, pode afirmar-se que os [seus] membros têm hoje o único oficio de adornar com o seu nome o anuário oficial. [...]

Na Espanha existiu também, vindo já do Antigo Regime, o Conselho de Estado político; mas está hoje transformado em órgão de consulta administrativa e tribunal supremo do contencioso administrativo.

Pode pois dizer-se que Portugal é o único país onde o Conselho de Estado político conserva a sua especial feição [...]". ${ }^{8}$

Acrescente-se, porém, que no Brasil Imperial, em particular durante o Segundo Reinado (1840-1889), o Conselho de Estado, embora também desempenhasse importantes funções administrativas, tinha uma grande relevância política, sendo mesmo designado por um contemporâneo como o "cérebro da monarquia". 9

Mas qual foi, afinal, o papel político efectivo do nosso Conselho de Estado? O Rei alinhava sempre com a opinião maioritária entre os seus conselheiros? E estes últimos eram um grupo de "espíritos políticos com maturidade e vigorosos", com uma intervenção activa na vida pública, ou, pelo contrário, exerciam o cargo a título honorífico, como "uma recompensa pelos serviços prestados, uma espécie de sinecura para a velhice"? ${ }^{10}$

Começando por aflorar este último aspecto, basta percorrer a lista dos conselheiros para nos apercebermos imediatamente que a maioria não só tinha um longo tirocínio parlamentar e ministerial, como continuava activa na "política militante", como se dizia na época. De facto, a prática constitucional conduziu a que a sua "quase totalidade [fosse] sempre constituída por políticos em evidência", ${ }^{11}$ com destaque para os principais vultos partidários..$^{12} \mathrm{~A}$ escolha dos putativos conselheiros era, aliás, um momento propício à intriga e às manobras políticas de bastidores. Quando ocorria uma vacatura, por motivo de morte, era comum o Rei ser confrontado com uma proposta do Governo em exercício, sobretudo se a relação de forças no seio do Conselho de Estado lhe era desfavorável, ou com as pretensões de políticos com ambições pessoais. Por vezes, a própria apresentação de um nome pelo Governo era motivo de celeumas intestinas, como sucedeu em $1887 \mathrm{com}$ a escolha do conde de S. Januário. ${ }^{13}$ Nem sempre, porém, o Rei atendia a essas sugestões ou cedia às pressões individuais. Em Outubro de 1857, D. Pedro V recusou liminarmente a nomeação de Passos Manuel, que tinha sido indicado pelo Governo da altura. ${ }^{14}$ Quase três 
anos depois, e logo a seguir ao falecimento de José Jorge Loureiro, Fontes Pereira de Melo apressou-se a escrever ao Rei a apresentar a sua candidatura para a vaga em aberto, mas D. Pedro V, que já não nutria especial simpatia pelo então ministro do Reino, e muito menos apreciou a "forma abrupta de pedir o que não é costume pedir", ${ }^{15}$ preferiu nomear o visconde de Sá da Bandeira.

Para contrariar a reconhecida tendência para a politização dos critérios de selecção dos membros do Conselho de Estado, que devia ser uma instituição acima das "paixões partidárias", foram feitas algumas propostas de alteração da sua composição, que nunca chegaram a concretizar-se. Em 1876, no manifesto programático do Partido Progressista, acenava-se com uma futura reorganização em que $2 / 3$ dos conselheiros seriam indivíduos que exercessem elevadas funções públicas, a designar por lei, e os restantes seriam escolhidos pelo Governo "entre pessoas de reconhecido mérito e capacidade". Três déca das depois, Trindade Coelho preconizaria uma solução semelhante, em que os conselheiros seriam recrutados entre "as sumidades hierárquicas da administração civil, da magistratura, das altas corporações docentes e científicas", ou, em alternativa, escolhidos pelas Cortes, como na antiga fórmula vintista. ${ }^{16}$

Decorrente do carácter vitalício do cargo e do limitado número de titulares, os longos anos de permanência em funções de vários conselheiros e os seus conhecidos vínculos político-partidários eram factores que determinavam uma certa previsibilidade e estabilidade das opiniões veiculadas pelo Conselho de Estado. ${ }^{17} \mathrm{O}$ recordista absoluto foi António Bernardo da Costa Cabral, que apenas com uma breve interrupção de um ano, por ter sido demitido (um caso excepcional) ${ }^{18}$ se manteve no Conselho de Estado durante 44 anos. Segue-se-lhe o duque de Saldanha, que exerceu o cargo durante cerca de 37 anos, mas com uma interrupção na vigência da Constituição setembrista, e António José de Ávila (futuro duque de Ávila e Bolama), que permaneceu em actividade perto de 30 anos consecutivos.

14 A influência real, concreta, do Conselho de Estado no processo político é ainda um assunto por desvendar, e tem sido um tema praticamente ignorado pela historiografia contemporânea. A razão de ser deste desinteresse ou silêncio historiográfico não se deve tanto, supomos, à desvalorização apriorística de um órgão tido como uma espécie de ornamento constitucional supérfluo, mas ao facto de serem muito escassas e dispersas as informações sobre a sua actividade publicadas quer na imprensa, quer na literatura política e memorialística da época. Além disso, os próprios livros de actas do Conselho de Estado, actualmente à consulta nos arquivos da Torre do Tombo, não só formam uma série incompleta, ${ }^{19}$ como as súmulas que fornecem das reuniões são em geral parcimoniosas e discretas.

O exame dos livros de actas e da própria cronologia das reuniões do Conselho de Estado revela todavia que quando estavam em causa "negócios graves" ou o exercício das atribuições do poder moderador, a audição do Conselho de Estado era um imperativo constitucional normalmente respeitado. ${ }^{20}$ Por exemplo, em Outubro de 1858, por ocasião do "ultimato" francês motivado pelo apresamento do navio Charles et Georges, o Conselho de Estado reuniu-se "por assim dizer quase que em sessão permanente". ${ }^{21}$ Quando estava em jogo a prorrogação das Cortes ou a dissolução da Câmara dos Deputados, também era regularmente ouvido. ${ }^{22}$ É, aliás, significativo que em 1870, logo após o pronunciamento militar chefiado pelo duque de Saldanha, este tenha solicitado a convocação do Conselho de Estado para ser decretado o adiamento das Cortes. ${ }^{23}$ Se o Rei seguia ou não a opinião veiculada pela "maioria" dos conselheiros, aí as informações são díspares. Eis alguns 
exemplos. Em Março de 1862, apesar do voto desfavorável da maioria dos seus conselheiros, o rei D. Luís autorizou o pedido de adiamento das sessões das Cortes soli citado pelo chefe do governo, o marquês de Loulé. ${ }^{24}$ Contudo, em finais desse mesmo ano, o parecer dos conselheiros parece ter sido crucial na recusa do Rei em aceitar o pedido de demissão apresentado pelo ministro da Guerra, visconde de Sá da Bandeira. Nos começos de 1890, a proposta de dissolução da Câmara dos Deputados apresentada pelo recémnomeado chefe do governo, António de Serpa Pimentel, foi recusada pela maioria dos conselheiros de Estado; não obstante, a proposta do governante teve a sanção régia. ${ }^{25}$ Por sua vez, em finais de 1893, uma maioria tangencial (6 contra 5) no Conselho de Estado pronunciou-se a favor da dissolução da câmara electiva, e esta foi decretada pelo Rei. ${ }^{26} \mathrm{Na}$ viragem do século, em Junho de 1900, a oposição "quase unânime" dos conselheiros de Estado ao projecto de reforma da Carta apresentado pelo governo progressista de José Luciano de Castro suscitou ao Rei fortes reservas quanto à constitucionalidade de uma revisão antecipada, o que acabou por ditar a queda do executivo. ${ }^{27}$

Este é um balanço ainda muito parcelar e com elementos de prova contraditórios, mas que indicia que as atribuições do Conselho de Estado não eram um mero sofisma ou formalidade constitucional, sem uma tradução política efectiva. Regularmente auscultado pelo Rei, em várias ocasiões o seu papel poderá ter sido determinante na formação da vontade régia. Ser conselheiro de Estado significava, assim, a possibilidade de intervir no topo do processo decisório, privando com o Rei e influenciando as suas atitudes e deliberações.

\section{Prosopografia dos conselheiros de Estado efectivos (1833-1910)}

17 Desde finais de 1833, quando o Conselho de Estado foi instituído por D. Pedro (Decreto de 19 de Setembro), até ao ocaso da Monarquia em 1910, foram empossados 73 conselheiros efectivos (vd. Quadro 2). Um universo restrito que coincide, em larga medida, com o núcleo central da elite governante do liberalismo monárquico. Traçamos, de seguida, a evolução do perfil sociodemográfico e político desse grupo, diferenciando três subperíodos: 1833-1850; 1851-1890; 1891-1910 (vd. Quadros 3,4 e 5). Os pontos de viragem intermédios são, por um lado, o início da Regeneração (1851) e, por outro, a crise de 1890-91, dois momentos que implicaram mudanças na dinâmica política e uma renovação parcial da elite governante.

\section{Origem geográfica}

O local de nascimento não é um factor que pré-determine as oportunidades de realização pessoal, nem é, só por si, um indicador consistente do arraigamento do indivíduo a um dado território. Independentemente dos laços familiares e de outros vínculos que prendem um indivíduo à sua terra de naturalidade, as etapas decisivas da sua formação e socialização, que lhe poderão rasgar novos horizontes, processam-se frequentemente alhures; não raro, também, o local de nascimento é meramente acidental, fruto de circunstâncias ocasionais, corno sucede, por exemplo, quando os progenitores têm profissões que obrigam a uma constante mobilidade territorial. 
19 Apesar destas limitações, a reconstituição das origens geográficas dos membros da elite governante num dado momento histórico é susceptível de revelar algumas regularidades e tendências significativas que ajudam a compreender as articulações entre espaço e poder político, nomeadamente a dinâmica das relações entre centro e periferia. Através dessa pesquisa é, assim, possível averiguar o grau de centralização ou de descentralização geográfica do recrutamento político, bem como identificar as parcelas do território nacio nal que são mais favoráveis à gestação de certas carreiras públicas (políticas e administrativas).

Analisando a proveniência geográfica dos conselheiros de Estado, o dado mais saliente é a indiscutível primazia de Lisboa (e arredores) como espaço de recrutamento (37,5\% do total). Particularmente expressiva durante o período da "longa" Regeneração (1851-1890), a hegemonia da capital sofre todavia uma quebra significativa nas duas últimas décadas do regime monárquico. A comparação com os padrões de recrutamento geográfico de outros subgrupos da elite governante (ministros, pares do reino, deputados, directoresgerais, governadores civis) revela que quanto mais elevados e selectivos são os cargos políticos, maior é também a tendência para se acentuar o peso relativo dos lisboetas, ${ }^{28}$ mercê da fixação e concentração na primeira cidade do país das famílias de estrato social mais elevado - assim, por exemplo, as antigas famílias aristocráticas, pelo menos desde o século XVIII, e diversamente do que sucedia em outros países europeus, residiam todas na capital, onde edificaram as suas residências permanentes. ${ }^{29}$ Entre os conselheiros oriundos de Coimbra, o pólo universitário e o segundo mais importante viveiro de recruta mento, ainda que tendencialmente em declínio, importa assinalar que alguns deles provinham de meios familiares ligados à vida académica local: o visconde de Algés era neto de um antigo reitor e filho de um doutor em Leis; António de Serpa Pimentel era filho de um lente de Direito; e Augusto César Barjona de Freitas, ele próprio professor de Direito, era também filho e sobrinho de lentes universitários.

\section{Perfil etário}

21 Posicionado junto ao vértice da hierarquia política, com funções de aconselhamento do monarca, o Conselho de Estado era naturalmente formado por personalidades com uma larga experiência de serviço público, o que implicava em geral que fossem escolhidas num escalão etário mais velho. ${ }^{30}$ Por esse motivo, e mercê também do carácter vitalício do cargo, os conselheiros de Estado eram, conjuntamente com os membros do pariato, o subgrupo da elite política onde eram mais acentuadas as tendências gerontocráticas.

Entre 1833 e 1850, a idade média à data da nomeação situa-se nos 55 anos; entre 1851 e 1890 sobe para os 59 anos; e de 1891 a 1910 regride para os 56 anos. No primeiro período, onde $1 / 4$ dos conselheiros tem menos de 50 anos, a relativa juventude do perfil etário reflecte a emergência de uma elite governante radicalmente nova, no contexto de implantação do regime liberal. No período seguinte, sob o signo do consenso e estabilidade da Regeneração, os critérios de selecção tendem a favorecer uma maior veterania. Já a recomposição da elite política suscitada pela crise de 1890-91 veio favorecer o rejuvenescimento do Conselho de Estado.

Particularizando um pouco as idades dos conselheiros à data da sua nomeação, verifica-se que os dois mais novos são João Franco, que ascendeu ao cargo com apenas 39 anos, e António Bernardo da Costa Cabral, que tinha 40 anos. Com menos de 45 anos, só foram nomeados mais sete: Lopo Vaz (41 anos); o marquês de Saldanha, o duque da Terceira e 
Ernesto Hintze Ribeiro (todos com 42 anos); José António Guerreiro (43 anos); José Bernardo da Silva Cabral e António José de Ávila (ambos com 44 anos). Olhando o reverso da medalha, urna dezena de indivíduos ingressou no Conselho de Estado já no crepúsculo da vida: um octogenário (João Baptista de Andrade, com 81 anos) e nove septuagenários João de Sousa Pinto de Magalhães (78 anos); Fernando Sousa Barradas, João Crisóstomo de Abreu e Sousa, António Sá Brandão e Luís Gomes da Costa (75 anos); o marquês do Funchal (73 anos); José Marcelino de Sá Vargas (72 anos); o visconde da Carreira (71 anos); e o conde do Sobral (70 anos).

\section{Credenciais académicas}

Num interessante estudo sobre a elite política do Brasil imperial, e a propósito das suas elevadas credenciais académicas, o historiador José Murilo de Carvalho define-a como "uma ilha de letrados num mar de analfabetos. ${ }^{31}$ Metáfora que se aplica ipsis verbis à sua congénere portuguesa da época, com quem partilha, aliás, outras características.

No Portugal oitocentista, onde persistiam altíssimas taxas de analfabetismo, e onde aqueles que tinham uma formação académica superior representavam um segmento muito restrito da população adulta e não dispunham de um leque muito variado de alternativas ocupacionais, era inevitável, por assim dizer, que os principais cargos da governação pública fossem disputados e ocupados por uma "elite ilustrada".

O principal centro de formação intelectual continuava a ser inegavelmente a Universidade de Coimbra, com relevo para a Faculdade de Direito, ${ }^{32}$ apesar da crescente importância das instituições de ensino superior de Lisboa, em particular a Escola do Exército. De realçar, a capilaridade existente entre a Universidade de Coimbra e a Escola do Exército: antes de ingressarem nesta última, vários militares obtinham o bacharelado na Faculdade de Matemática. ${ }^{33}$

No caso especifico dos conselheiros de Estado, os juristas eram indiscutivelmente a categoria mais representada, seguindo-se-lhe a larga distância os indivíduos formados pelas academias militares Dos doze casos identificados como não tendo completado um curso superior, metade eram aristocratas (que, seguindo um padrão tradicional, tinham sido educados por tutores particulares); dos restantes, pelo menos dois (Rodrigo da Fonseca Magalhães e José Jorge Loureiro) tinham chegado a frequentar a Universidade.

\section{Actividade profissional}

28 A esmagadora maioria dos conselheiros eram personalidades com uma longa carreira de serviço público, destacando-se os militares de alta patente e os magistrados judiciais no topo da carreira como as principais fieiras de recrutamento. Recorde-se, aliás, que no regulamento do Conselho de Estado de 1845 se preconizava a selecção dos que se tivessem distinguido "por talentos e provada capacidade na gerência dos negócios públicos em algum lugar superior do Estado" (art. $3^{\circ}$ ). A omnipresença do funcionalismo público só declina no último subperíodo, quando os profissionais liberais e os capitalistas (proprietários e negociantes) representam em conjunto cerca de $28 \%$. Em termos de evolução das várias categorias ocupacionais, há ainda a assinalar a clara tendência para um crescente protagonismo dos professores universitários, bem como o súbito declínio da importância dos militares nas duas últimas décadas. 
29 As informações que foi possível recolher sobre as profissões dos progenitores dos conselheiros revelam que muitos deles já eram servidores do Estado, com predomínio igualmente dos meios castrense e da magistratura. O que significa que, em alguns casos, houve uma clara reprodução familiar de vocações. A título de curiosidade mencione-se um exemplo, ainda que excepcional, em que essa "hereditariedade" teve também uma tradução política: o general de divisão Carlos Maria de Caula e o seu pai, um antigo marechal de campo, exerceram em momentos distintos o cargo de conselheiros de Estado.

\section{Recrutamento social e títulos nobiliárquicos}

30 Quanto aos meios sociais de origem dos conselheiros, é indiscutível o predomínio dos estratos superiores e privilegiados, não só devido à importância relativa dos aristocratas e fidalgos de linhagem, mas porque muitos dos membros da "classe média" eram filhos de gente com recursos económicos e prestígio social e intelectual, por vezes também com ramificações familiares e sólidas relações de sociabilidade nos círculos da nobreza.

31 Não admira, por isso, que os conselheiros de Estado fossem, a seguir aos pares do reino, o subgrupo da elite política onde era maior a percentagem de indivíduos com títulos nobiliárquicos. ${ }^{34}$ Mas, com excepção dos velhos aristocratas, ${ }^{35}$ todos os outros ostentavam títulos de fresca data, sendo alguns deles representantes dessa burguesia "ensanefada de ouropéis fidalgos", para utilizar a expressão sarcástica de Alexandre Herculano. ${ }^{36}$ Convém notar, porém, que à medida que o tempo avança vai decaindo continuada e drasticamente a proporção de novos conselheiros que ostentam um título nobiliárquico: entre o primeiro e o terceiro subperíodo diminui de $37,5 \%$ para $11 \%$.

\section{Carreira política}

32 Como se depreende de quanto foi dito, a ascensão ao Conselho de Estado constitui, em regra, o ápice de uma longa carreira política, normalmente iniciada nas lides parlamentares, e com frequência prosseguida no exercício de funções governativas.

O elenco dos principais cargos políticos desempenhados pelos conselheiros, antes da sua nomeação para este alto cargo, é descrito em pormenor no Quadro 5. Fazendo uma síntese global dos dados fundamentais, verifica-se que a esmagadora maioria dos conselheiros tinha um tirocínio parlamentar mais ou menos prolongado, como deputados e/ou pares do reino, e experiência ministerial. Foram muito poucos, porém, aqueles que chefiaram o executivo (José Jorge Loureiro, Joaquim António de Aguiar e Venceslau Pereira Lima) antes de se tornarem conselheiros de Estado. A trajectória inversa era a mais comum, sendo por isso o Conselho de Estado um alfobre de putativos primeiro-ministros.

Os três únicos conselheiros sem currículo político, a nível parlamentar ou ministerial, são José de Cupertino de Aguiar Ottolíni, o $1^{\circ}$ visconde da Carreira e o general Carlos Maria de Caula. $O$ primeiro era um conceituado magistrado, que exerceu quase ininterruptamente o cargo de Procurador-Geral da Coroa de 1838 a 1859; segundo uma fonte da época, Ottoliní só aceitou entrar para o Conselho de Estado após insistentes convites do rei D. Pedro V. ${ }^{37} \mathrm{O}$ visconde da Carreira, um diplomata e tutor do infante D. Luís, embora tenha chegado a ser nomeado ministro em duas ocasiões, acabou por não tomar posse do cargo. Por último, o general Carlos Maria de Caula, que recusou sempre as propostas que lhe fizeram para ascender ao pariato ou para sobraçar a pasta da Guerra, era ajudante de campo de D. Pedro V e, após a sua morte, de D. Luís. 
35 A finalizar, uma nota comparativa sobre o cursus honorum político dos conselheiros de Estado. No Brasil imperial, dos 72 indivíduos que integraram o Conselho de Estado entre 1841 e 1889, apenas $5(6,9 \%)$ não tinham prévia experiência em cargos políticos, ${ }^{38}$ o que corresponde a uma percentagem idêntica à dos seus congéneres portugueses nomeados entre 1851 e 1890.

Quadro 1 - Número de reuniões do Conselho de Estado (1834-1904)

\begin{tabular}{cccccc}
\hline Ano & N. & Ano & N. & Ano & N. $^{\mathbf{0}}$ \\
\hline $1834^{*}$ & 31 & 1868 & 14 & 1896 & 9 \\
1835 & 17 & 1869 & 15 & 1897 & 7 \\
& & 1870 & 17 & 1898 & 7 \\
1842 & 20 & 1871 & 15 & 1899 & 11 \\
1843 & 13 & 1872 & 5 & 1900 & 6 \\
& & 1873 & 7 & 1901 & 5 \\
1855 & 17 & 1874 & 6 & 1902 & 7 \\
1856 & 17 & & & 1903 & 8 \\
1857 & 16 & 1889 & 14 & 1904 & 8 \\
1858 & 18 & 1890 & 14 & & \\
1859 & 17 & 1891 & 15 & & \\
1861 & 20 & 1892 & 10 & & \\
1862 & 17 & 1893 & 10 & & \\
1863 & 12 & 1894 & 4 & & \\
1864 & 13 & 1895 & 4 & & \\
\hline
\end{tabular}

Fonte: Actas do Conselho de Estado, Livros 1 a 5 (IAN/TT, C.F. 77).

* Incluindo as duas primeiras sessões do Conselho de Estado realizadas em finais de 1833. 
Quadro 2 - Conselheiros de Estado efectivos (1833-1910)*

\begin{tabular}{|c|c|c|}
\hline N. ${ }^{\circ}$ & Nome & $\begin{array}{c}\text { Data de } \\
\text { nomeação }\end{array}$ \\
\hline 1 & Francisco Manuel Trigoso de Aragão Morato & 20.09 .1833 \\
\hline 2 & Carlos Frederico da Caula & 20.09 .1833 \\
\hline 3 & Duque de Palmela & 20.09 .1833 \\
\hline 4 & Marquês de Saldanha & 20.09 .1833 \\
\hline 5 & Fernando Luís Pereira de Sousa Barradas & 20.09 .1833 \\
\hline 6 & Francisco Simões Margiochi & 20.09 .1833 \\
\hline 7 & José António Guerreiro & 20.09 .1833 \\
\hline 8 & Marquês do Funchal $\left(1 .^{\circ}\right)$ & 20.09 .1833 \\
\hline 9 & Agostinho José Freire & 24.07.1834 \\
\hline 10 & Fr. Francisco de S. Luís (bispo-conde de Arganil) & 24.07.1834 \\
\hline 11 & Duque da Terceira & 24.07 .1834 \\
\hline 12 & José da Silva Carvalho & 24.07 .1834 \\
\hline 13 & Conde de Vila Real (1. $\left.{ }^{\circ}\right)$ & 20.05 .1835 \\
\hline 14 & Manuel Gonçalves de Miranda & 20.05 .1835 \\
\hline 15 & Marquês de Valença (5.') & 29.09 .1835 \\
\hline 16 & Rodrigo da Fonseca Magalhães & 14.02.1842 \\
\hline 17 & António Bernardo da Costa Cabral' ${ }^{\prime}$ & 30.12 .1843 \\
\hline 18 & Barão de Chanceleiros (1. $\left.{ }^{\circ}\right)$ & 12.08 .1845 \\
\hline 19 & D. Guilherme H. de Carvalho (bispo de Leiria) & 13.11 .1845 \\
\hline 20 & Conde do Sobral $\left(1 . .^{\circ}\right)$ & 23.12.1845 \\
\hline 21 & José Bernardo da Silva Cabral & 26.02 .1846 \\
\hline 22 & Manuel Duarte Leitão & 10.10 .1848 \\
\hline 23 & António José de Ávila & 21.07 .1850 \\
\hline 24 & Visconde de Castro (1.9) & 23.07 .1850 \\
\hline 25 & Conde do Lavradio $\left(2 .^{\circ}\right)$ & 08.10 .1857 \\
\hline 26 & José Jorge Loureiro & 08.10 .1857 \\
\hline 27 & Visconde de Algés (1. ${ }^{\circ}$ ) & 09.10 .1857 \\
\hline 28 & José Cupertino de Aguiar Ottolíni & 12.03 .1858 \\
\hline 29 & João de Sousa Pinto de Magalhães & 26.05 .1858 \\
\hline 30 & Visconde da Carreira $\left(1 .^{\circ}\right)$ & 08.01 .1859 \\
\hline 31 & Marquês de Loulé & 13.04.1859 \\
\hline 32 & Joaquim António de Aguiar & 30.04 .1860 \\
\hline 33 & Visconde de Sá da Bandeira & 09.07 .1860 \\
\hline 34 & Júlio Gomes da Silva Sanches & 03.04 .1865 \\
\hline 35 & José Feliciano da Silva e Costa & 05.05 .1865 \\
\hline 36 & António Maria Fontes Pereira de Melo & 25.04 .1866 \\
\hline 37 & Anselmo José Braamcamp & 29.08 .1866 \\
\hline 38 & Filipe Folque & 18.07 .1870 \\
\hline 39 & José Maria Eugénio de Almeida & 18.07.1870 \\
\hline
\end{tabular}

\begin{tabular}{|c|c|c|}
\hline N. ${ }^{\circ}$ & Nome & $\begin{array}{c}\text { Data de } \\
\text { nomeação }\end{array}$ \\
\hline 40 & Carlos Bento da Silva & 22.01 .1871 \\
\hline 41 & Conde do Casal Ribeiro $\left(1^{\circ}\right)$ & 06.05 .1872 \\
\hline 42 & João B. da Silva Ferrão de Carvalho Martens & 28.05 .1874 \\
\hline 43 & José Marcelino de Sá Vargas & 31.12 .1874 \\
\hline 44 & Marquês de Fícalho $\left(2^{\circ}\right)$ & 28.05 .1875 \\
\hline 45 & António de Serpa Pímentel & 21.01 .1876 \\
\hline 46 & João de Andrade Corvo & 14.09 .1876 \\
\hline 47 & Carlos Maria de Caula & 23.11 .1876 \\
\hline 48 & Conde de Valbom & 22.11 .1878 \\
\hline 49 & José da Silva Mendes Leal Jr. & 06.05 .1881 \\
\hline 50 & Augusto Barjona de Freitas & 19.11.1885 \\
\hline 51 & José Luciano de Castro & 18.02 .1886 \\
\hline 52 & João Crisóstomo de Abreu e Sousa & 02.10 .1886 \\
\hline 53 & Conde de S. Januário & 21.06 .1887 \\
\hline 54 & Henrique de Barros Gomes & 07.11 .1889 \\
\hline 55 & Lopo Vaz de Sampaio e Melo & 20.02 .1890 \\
\hline 56 & Ernesto Rodolfo Hintze Ribeiro & 19.12.1891 \\
\hline 57 & José Vicente Barbosa du Bocage & 27.05 .1892 \\
\hline 58 & Conde de Ficalho $\left(4 .^{\circ}\right)$ & 04.05 .1893 \\
\hline 59 & João Franco & 17.01 .1895 \\
\hline 60 & António Emílio Correia de Sá Brandão & 20.06 .1896 \\
\hline 61 & Júlio Marques de Vilhena & 20.06 .1896 \\
\hline 62 & Francisco António da Veiga Beirão & 24.11.1898 \\
\hline 63 & José Baptista de Andrade & 29.03 .1900 \\
\hline 64 & Frederico de Gusmão Correia Arouca & 28.07 .1900 \\
\hline 65 & Marquês de Soveral $\left(1^{\circ}\right)$ & 21.02 .1901 \\
\hline 66 & Luís Augusto Pimentel Pinto & 01.06 .1901 \\
\hline 67 & Luís Frederico de Bivar Gomes da Costa & 13.03.1902 \\
\hline 68 & António Cândido Ribeiro da Costa & 13.03 .1902 \\
\hline 69 & Alberto António de Morais Carvalho & 07.05 .1903 \\
\hline 70 & António de Azevedo Castelo Branco & 17.09.1904 \\
\hline 71 & José J. de Abreu do Couto de Amorim Novais & 19.08.1907 \\
\hline 72 & José Adolfo de Melo e Sousa & 14.11.1907 \\
\hline 73 & Venceslau de Sousa Pereira Lima & 22.12.1909 \\
\hline
\end{tabular}

FONTE: MANUEL PINTO dOS SANTOS, ORg., MONARQUIA CONSTITUCIONAL. ORgANIZAÇÃo E RELAÇÕES DO PODER gOVERNAMENTAL COM A CÂMARA DOS DEPUTADOS, 1834-1910, LISBOA, ASSEMBLEIA DA REPÚBLICA, 1986, ANEXO I. 
37 chegou a tomar posse.

38 restituído por Decreto de 22 de Dezembro de 1847.

Quadro 3. Número de conselheiros de Estado efectivos nomeados entre 1833 e 1910

\begin{tabular}{|c|c|c|c|c|c|c|c|}
\hline \multicolumn{2}{|c|}{$1833-1850$} & \multicolumn{2}{c|}{$1857-1890$} & \multicolumn{2}{c|}{$1891-1909$} & \multicolumn{2}{c|}{ Total } \\
\hline $\mathrm{N}^{\circ}$ & $\%$ & $\mathrm{~N}^{\circ}$ & $\%$ & $\mathrm{~N}^{\circ}$ & $\%$ & $\mathrm{~N}^{\circ}$ & $\%$ \\
\hline 24 & 32,9 & 31 & 42,5 & 18 & 24,6 & 73 & 100,0 \\
\hline
\end{tabular}

Quadro 4. Características sociodemográficas dos conselheiros de Estado efectivos*

\begin{tabular}{|c|c|c|c|c|c|c|c|c|}
\hline \multirow{2}{*}{$\begin{array}{c}\text { Caracteristicas } \\
\text { sociodemográficas }\end{array}$} & \multicolumn{2}{|c|}{$1833-1850$} & \multicolumn{2}{|c|}{$1857-1890$} & \multicolumn{2}{|c|}{ 1891-1909 } & \multicolumn{2}{|c|}{ Total } \\
\hline & $\mathrm{N}^{\circ}$ & $\%$ & $\mathrm{~N}^{\circ}$ & $\%$ & $\mathrm{~N}^{\circ}$ & $\%$ & $\mathrm{~N}^{\circ}$ & $\%$ \\
\hline \multicolumn{9}{|l|}{ NATURALIDADE*** } \\
\hline Lisboa e arredores & 6 & 26,1 & 17 & 54,8 & 4 & 22,2 & 27 & 37,5 \\
\hline Porto & 1 & 4,3 & 1 & 3,2 & 2 & 11,1 & 4 & 5,6 \\
\hline Coimbra & 3 & 13,0 & 4 & 12,9 & 0 & 0,0 & 7 & 9,7 \\
\hline Resto do país & 11 & 47,8 & 9 & 29,0 & 12 & 66,7 & 32 & 44,4 \\
\hline Estrangeiro e antigas colónias & 2 & 8,7 & 0 & 0,0 & 0 & 0,0 & 2 & 2,8 \\
\hline \multicolumn{9}{|l|}{ IDADE } \\
\hline 39-49 anos & 6 & 25,0 & 5 & 16,1 & 3 & 16,7 & 14 & 19,2 \\
\hline $50-60$ anos & 11 & 45,8 & 13 & 41,9 & 10 & 55,5 & 34 & 46,6 \\
\hline$>60$ anos & 7 & 29,2 & 13 & 41,9 & 5 & 27,8 & 25 & 34,2 \\
\hline Idade média (anos) & 55 & - & 59 & - & 56 & - & 57 & - \\
\hline \multicolumn{9}{|l|}{ EDUCAÇÃO } \\
\hline Sem curso superior & 4 & 16,7 & 7 & 22,6 & 1 & 5,6 & 12 & 16,4 \\
\hline Com curso superior & 20 & 83,3 & 24 & 77,4 & 17 & 94,4 & 61 & 83,6 \\
\hline Direito & 12 & 50,0 & 13 & 41,9 & 11 & 61,1 & 36 & 49,3 \\
\hline Matemática/Filosofia & 4 & 16,7 & 2 & 6,4 & 1 & 5,5 & 7 & 9,6 \\
\hline Militar & 3 & 12,5 & 7 & 22,6 & 2 & 11,1 & 12 & 16,4 \\
\hline Outros & 1 & 4,1 & 2 & 6,4 & 3 & 16,7 & 6 & 8,2 \\
\hline \multicolumn{9}{|l|}{ PROFISSÃO } \\
\hline Funcionário público & 2 & 8,3 & 6 & 19,3 & 2 & 11,1 & 10 & 13,7 \\
\hline Professor universitário & 1 & 4,2 & 4 & 12,9 & 4 & 22,2 & 9 & 12,3 \\
\hline Magistrado judicial & 7 & 29,2 & 6 & 19,3 & 4 & 22,2 & 17 & 23,3 \\
\hline Diplomata & 2 & 8,3 & 2 & 6,4 & 1 & 5,5 & 5 & 6,8 \\
\hline Militar & 8 & 33,3 & 10 & 32,3 & 2 & 11,1 & 20 & 27,4 \\
\hline Padre & 2 & 8,3 & 0 & 0,0 & 0 & 0,0 & 2 & 2,7 \\
\hline Profissão liberal & 0 & 0,0 & 0 & 0,0 & 3 & 16,7 & 3 & 4,1 \\
\hline Proprietário / Negociante & 2 & 8,3 & 3 & 9,7 & 2 & 11,1 & 7 & 9,6 \\
\hline TÍTULO NOBILIÁRQUICO & & & & & & & & \\
\hline Sem título & 15 & 62,5 & 22 & 71,0 & 16 & 88,9 & 52 & 71,2 \\
\hline Com titulo & 9 & 37,5 & 9 & 29,0 & 2 & 11,1 , & 21 & 28,8 \\
\hline
\end{tabular}

39 * À data da nomeação. As percentagens são sempre calculadas em relação ao total de indivíduos nomeados em cada período.

** Não foi possível apurar o local de nascimento de Carlos Caula, nomeado em 1833, pelo que o número total de casos com informação é de 72. 
Quadro 5. Experiência política dos conselheiros de Estado efectivos*

\begin{tabular}{|c|c|c|c|c|c|c|c|c|}
\hline \multirow{2}{*}{$\begin{array}{c}\text { Experiência } \\
\text { politica }\end{array}$} & \multicolumn{2}{|c|}{$1833-1850$} & \multicolumn{2}{|c|}{$1857-1890$} & \multicolumn{2}{|c|}{$1891-1909$} & \multicolumn{2}{|c|}{ Total } \\
\hline & $\mathrm{N}^{\mathrm{o}}$ & $\%$ & $\mathrm{~N}^{\mathrm{o}}$ & $\%$ & $\mathrm{~N}^{\circ}$ & $\%$ & $\mathrm{~N}^{\circ}$ & $\%$ \\
\hline Sem experiência política & 1 & 4,2 & 2 & 6,4 & 0 & 0,0 & 3 & 4,1 \\
\hline Com experiência política & 23 & 95,8 & 29 & 93,6 & 18 & 100,0 & 70 & 95,9 \\
\hline Governador civil & 0 & 0,0 & 1 & 3,2 & 3 & 16,7 & 4 & 5,5 \\
\hline Governador colonial & 0 & 0,0 & 0 & 0,0 & 1 & 5,5 & 1 & 1,4 \\
\hline Deputado elou Par & 17 & 70,8 & 27 & 87,1 & 18 & 100,0 & 62 & 84,9 \\
\hline Ministro & 19 & 79,2 & 26 & 83,9 & 14 & 77,8 & 59 & 80,8 \\
\hline Presidente do Conselho & 0 & 0,0 & 3 & 9,7 & 1 & 5,5 & 4 & 5,5 \\
\hline
\end{tabular}

41

\section{NOTAS}

1. A criação do Conselho de Estado foi logo prevista nas "Bases" da futura Constituição aprovadas pelas Cortes Extraordinárias e Constituintes em 9 de Março de 1821, que serviram pro visoriamente de Lei fundamental. Em 2 de Outubro de 1821 foi publicado o regimento do Conselho de Estado, que ficou então composto por oito conselheiros, escolhidos pelo Rei a partir de uma lista proposta pelas Cortes. Sobre a composição e as atribuições do Conselho de Estado no liberalismo oitocentista português, vd. o recente estudo de Maria da Glória Dias Garcia, Do Conselho de Estado ao actual Supremo Tribunal Administrativo, Lisboa, Supremo Tribunal Administrativo, 1998.

2. Segundo a Carta Constitucional, "o Poder Moderador [...] compete privativamente ao Rei" (art. 71ํ) e "o Rei é o chefe do Poder Executivo, e o exercita pelos seus ministros de Estado" (art. 75을.

3. Vd., em especial, José Tavares, 0 poder governamental no direito constitucional portuguez, Coimbra, Imprensa Académica, 1909, pp. 244 e 248-249, e Jorge Miranda, Conselho de Estado, Coimbra, Atlântida, 1970, p. 5.

4. As bases desta reforma foram estabelecidas na Lei de 3 de Maio de 1845 , sendo depois con cretizadas pelo Regimento de 16 de Julho desse ano; uma regulamentação definitiva, que in troduziu apenas algumas alterações de pormenor, seria decretada em 9 de Janeiro de 1850 ( $v d$. Joaquim Tomás Lobo de Ávila, Estudos de Administração, Lisboa, Typ. Universal, 1874, pp. 279-283, e Regulamento do Conselho de Estado..., Lisboa, Imprensa Nacional, 1850). De assinalar que, na mesma altura, se estabeleceu em Espanha, pela Lei de 6 de Julho de 1845, o Consejo Real (a partir de 1858 designado Consejo de Estado), um órgão supremo de consulta para os assuntos administrativos e do contencioso (vd. Tomás Ramón Fernández e Juan Alfonso Santamaria, compil., Legislación administrativa española del siglo XIX, Madrid, Instituto de Estudios Administrativos, 1977, pp. 155-156, e Juan Ramón Fernandez Torres, La formación historica de la jurisdicción contenciosoadministrativa (1845-1868), Madrid, Editorial Civitas, 1998, pp. 265 e segs.). [Agradeço a Javier Moreno Luzón as informações bibliográficas sobre o Conselho de Estado em Espanha]. 
5. Reforma decretada em 9 de Junho de 1870. Em finais de 1868, num contexto de crise financeira que recomendava a contenção das despesas públicas, um decreto datado de 31 de Dezembro determinara a redução de doze para oito do número de conselheiros efectivos, a concretizar-se à medida que fossem ocorrendo vacaturas. Esta medida tornou-se desnecessária a seguir à reforma de 1870, uma vez que os conselheiros efectivos deixaram de ser remunerados. Assinale-se, uma vez mais, a sincronia com as reformas institucionais realizadas em Espanha: em finais de 1868, a jurisdição contenciosa foi transferida do Consejo de Estado para o Tribunal Supremo.

6. José Tavares, ibidem, p. 284.

7. Vd. José Silvestre Ribeiro, compil. e anot., Resoluções do Conselho de Estado na secção do contencioso administrativo, 18 vols., Lisboa, Imprensa Nacional, 1854-1874.

8. Ob. cit., pp. 246-248. Para um aprofundamento do estudo comparado, vd. E. Laferrière, "Conseil d'Etat", in Maurice Block, dir., Dictionnaire générale de la politique, 1, Paris, O. Lorenz LibraireEditeur, 1873, pp. 470-480; Almeric Fitzroy, The history of the Privy Council, Londres, J. Murray, 1928; José Maria Cordero Torres, El Consejo de Estado. Su trayectoria y perspectivas en España, Madrid, Instituto de Estudios Políticos, 1944; Marie-Christine Kessler, Le conseil d'Etat, Paris, A. Colin, 1968; e AAVV, Studi per il centocinquantenario del Consiglio di Stato, 3 vols., Roma, Instituto poligrafico e Zecca del Stato, 1981.

9. A expressão de Joaquim Nabuco é citada pelo historiador José Murilo de Carvalho, que também sustenta ser o Conselho de Estado a "organização estratégica para se estudar o pensamento da elite política do Império" (in Teatro de sombras: a política imperial, Rio de Janeiro, Edições Vértice, 1988, p. 107).

10. Expressões pedidas de empréstimo a Johann $\mathrm{K}$. Bluntschli, Le droit public général, Paris, Librairie Guillaumin, 1881, p. 179.

11. José Tavares, ibidem, p. 244.

12. A título de exemplo, refira-se que uma vez consumada a ascensão de José Luciano de Castro à chefatura máxima do Partido Progressista (1885), a primeira vaga aberta no Conselho de Estado foi preenchida com o seu nome. Alguns anos mais tarde, o próprio Luciano de Castro recordou que fora "justamente na qualidade de chefe daquele partido, [que] havia sido nomeado conselheiro de Estado pelo Rei" (in Actas do Conselho de Estado, IAN/TT, Livro 5, sessão de 7 de Novembro de 1893).

13. Os ecos desse conflito chegam-nos através de uma carta inédita de José Luciano de Castro para o seu correligionário Mariano de Carvalho, datada de 21 de Julho de 1887 (Espólio Mariano de Carvalho, Biblioteca Nacional de Portugal).

14. Vd. Júlio de Vilhena, D. Pedro V e o seu reinado, II, Coimbra, Imprensa da Universidade, 1921, pp. 424-427.

15. Carta de D. Pedro V ao visconde da Luz, de 3 de Julho de 1860 (transcrita in Júlio de Vilhena, ibidem, p. 90).

16. Manual politico do cidadão portuguez, Lisboa, Parceria A.M. Pereira, 1906, pp. 501-502.

17. Apesar da nomeação a título vitalício dos seus membros, a Câmara dos Pares era muito mais permeável às flutuações de opinião e dos equilíbrios de força, não só pela existência (excepto num curto período) de pares por direito hereditário, mas sobretudo por não haver restrições à nomeação de novos pares (até 1885), o que facilitava as célebres "fornadas".

18. Vd. Clemente José dos Santos, Estatisticas e biographias parlamentares portuguezas, I, Porto, Typ. do "Commercio do Porto", 1887, p. 543.

19. Os livros de actas do Conselho de Estado (IAN/TT, C.F. 77) compreendem os seguintes pe ríodos: Livro 1 (19.10.1821 a 31.5.1823; 15.11 .1833 a $5.8 .1836 ; 12.2 .1842$ a 20.4.1844); Livro 2 (15.5.1854 a 23.11.1859); Livro 3 (28.7.1860 a 7.4.1865); Livro 4 (29.3.1867 a 30.6.1875); Livro 5 (29.11.1888 a 11.5.1905).

20. Para uma estatística (ainda incompleta) da frequência anual das reuniões do Conselho de Es tado, vd. Quadro 1. Durante o Cabralismo, como denunciou Joaquim António de Aguiar, o 
Conselho de Estado terá sido "desprezado", não sendo convocado em situações "em que a Carta expressamente o exige" (in Discurso do sr. Deputado[...] pronunciado nas sessões de 31 de Outubro, e 2 de Novembro de 1844, Lisboa, Imprensa Nacional, 1845, p. 81).

21. Vd. Manuel Pinheiro Chagas, dir., Historia de Portugal Popular e Ilustrada, XII, Lisboa, Empreza da Historia de Portugal, 1907, p. 142 (volume da autoria de Marques Gomes); esta obra é uma das que contém um maior volume de informações, ainda que dispersas, sobre a acção política do Conselho de Estado. Vd. também Fortunato de Almeida, A questão do apresamento da barca Charles et Georges e o Conselho de Estado, separata da Revista de História, Coimbra, 1917, e Eduardo dos Santos, A questão da barca Charles et Georges, Lisboa, Instituto de Investigação Científica Tropical, 1987, capítulo 5.

22. Por exemplo, entre 31 de Maio e 3 de Julho de 1889, o Conselho de Estado foi auscultado cinco vezes sobre outros tantos pedidos governamentais de prorrogação das Cortes (vd. Actas do Conselho de Estado, Livro 5).

23. Vd. Actas do Conselho de Estado, Livro 4, sessão de 21 de Maio de 1870.

24. Vd. Actas do Conselho de Estado, Livro 3, sessão de 17 de Março de 1862.

25. Vd. Actas do Conselho de Estado, Livro 5, sessão de 20 de Janeiro de 1890.

26. Vd. Actas do Conselho de Estado, Livro 5, sessão de 7 de Novembro de 1893. A consonância entre a opinião da "maioria" no Conselho de Estado e a deliberação régia ocorreu também, por exemplo, nas dissoluções da câmara electiva decretadas em 1900, 1901 e 1904 (vd. Actas do Conselho de Estado, Livro 5, sessões de 25 de Outubro de 1900, 4 de Junho de 1901 e 20 de Abril de 1904).

27. Vd. António Cabral, Cartas d'el rei D. Carlos a José Luciano de Castro, Lisboa, Portugal-Brasil Sociedade Editora, s.d. [1927], p. 263.

28. Vd. Pedro Tavares de Almeida, A construção do Estado Liberal. Elite política e burocracia na Regeneração (1851-1890), mimeo., Lisboa, FCSH-UNL, 1995, Parte I.

29. Vd. Adrien Balbi, Essai statistique sur le royaume de Portugal..., Paris, Rey et Gravier, 1822, p. 163, e Nuno Gonçalo Monteiro, "Poder senhorial, estatuto nobiliárquico e aristocracia", in José Matoso, dir., História de Portugal, IV, Lisboa, Círculo de Leitores, 1993, p. 372.

30. De assinalar que o Regulamento do Conselho de Estado de 1845 estabeleceu os 35 anos como limite mínimo de idade.

31. A construção da ordem. A elite política imperial, Rio de Janeiro, Editora Campus, 1980, p. 51.

32. A estatística global do movimento de matrículas na Universidade de Coimbra ao longo de todo o século XIX revela que mais de metade da população estudantil $(62,6 \%)$ frequentou as Faculdades Jurídicas (vd. Manuel Augusto Rodrigues, A Universidade de Coimbra. Marcos da sua história, Coimbra, Arquivo da Universidade, 1991, pp. 191-193). Quanto ao número de bacharéis formados na Universidade de Coimbra, desde finais do século XVIII até 1890, os bacharéis em Direito representaram sempre mais de $70 \%$ do total (vd. Maria Eduarda Cruzeiro, Action symbolique et formation scolaire. L'Université de Coimbra et sa Faculté de Droit dans la seconde moitié du XIXe siècle, mimeo, Paris, 1990, p. 526).

33. Como esclarece o visconde de Vila-Maior, "a legislação actual estabelece na Faculdade de Matemática dois cursos distintos - o curso geral e o curso preparatório para as escolas de aplicação [...] principalmente destinado para habilitar os alunos militares com os conhecimentos das ciências matemáticas e físicas, necessários para a sua entrada na Escola do Exército" (in Exposição succinta da organisação actual da Universidade de Coimbra, Coimbra, Imprensa da Universidade, 1877, pp. 183-185).

34. Assim, por exemplo, entre 1851 e 1890, eram titulares $38 \%$ dos pares de nomeação régia, $29 \%$ dos conselheiros de Estado, 19\% dos ministros e 9\% dos deputados (vd. Pedro Tavares de Almeida, ibidem, Parte I).

35. Dos descendentes da aristocracia de corte, o conde de Vila Real (cujo título foi atribuído em 1823) era o único cujo pai não tinha título de grandeza: trata-se, no entanto, de uma das raras 
casas de fidalgos de província que no decurso do século XVIII se foi integrando na primeira nobreza de corte. [Informação prestada por Nuno Gonçalo Monteiro, a quem agradeço].

36. Opusculos, I, Lisboa, Casa da Viuva Bertrand, 1873, p. 21.

37. Sobre a biografia do conselheiro Ottoliní, vd. a notícia necrológica publicada no Diario do Governo, 22 de Março de 1859.

38. Vd. José Murilo de Carvalho, Teatro de sombras..., p. 108 (tabela XI).

\section{RESUMOS}

O artigo descreve sinteticamente as mudanças observadas nas funções e composição do Conselho de Estado durante a Monarquia Constitucional, procurando indagar a relevância política de uma instituição concebida desde o início para aconselhar o monarca. Não obstante a parcimónia das fontes coevas, e até alguns exemplos contraditórios, parece inquestionável que em vários momentos críticos as decisões políticas do monarca foram influenciadas pela opinião dominante no Conselho de Estado. A finalizar, o artigo apresenta uma biografia colectiva dos 73 indivíduos que foram nomeados conselheiros de Estado efectivos entre 1833 e 1910 - e que podemos definir como o núcleo central da elite governante -, focando algumas características sociodemográficas (naturalidade, idade, educação, profissão, títulos nobiliárquicos) e tipos de experiência política.

This article summarises the transformations in the State Council's functions and membership throughout the Portuguese Constitutional Monarchy, and makes a preliminary attempt to scruti nise the political role played by an institution designed since its inception to advise the monarch. In spite of the parsimony of contemporary sources, and even contradictoiy empirical evidence, it seems indisputable that in several critical occasions the monarch's political decisions were influenced by the dominant view in the State Council. Finally, the article presents the collective biography of the 73 individuals appointed to the State Council between 1833 and 1910 - who may be defined as the inner circle of the ruling elite - focusing on basic background features (birthplace, age, education, occupation, and noble titles) and types of political experience.

\section{ÍNDICE}

Keywords: State Council, political elite, liberalism, Portugal

Palavras-chave: Conselho de Estado, elite política, liberalismo, Portugal

\section{AUTOR}

\section{PEDRO TAVARES DE ALMEIDA}

DEP - FCSH.

Licenciado em História e doutorado em Sociologia Política, é Professor do Departamento de Estudos Políticos da FCSH-UNL. Foi investigador visitante do Center of International Studies da Universidade de Princeton (1997) e membro do comité director de «EURELITE» (European Political Elites in Comparison), uma rede de investigação da Fundação Europeia de Ciência (2001-2004). As 
suas investigações têm incidido sobre os processos de construção do Estado moderno, a história eleitoral e o recrutamento das elites políticas e administrativas. Autor de vários estudos,

publicados em Portugal e no estrangeiro, recentemente co-dirigiu as obras colectivas Lei e Ordem (Lisboa, Livros Horizonte, 2006), Quem Governa a Europa do Sul?

(Lisboa, ICS, 2006; tradução do original em inglês) e Burocracia, Estado e Território (Lisboa, Livros Horizonte, 2006). 